\title{
Microstructures and Mechanical Properties of MIG Welding Joint of 7005 Aluminum Alloy
}

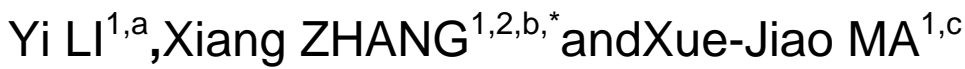 \\ ${ }^{1}$ Jiangsu Xuzhou Engineering Machinery Institute, Xuzhou, Jiangsu, 221004, China \\ ${ }^{2}$ School of Mechatronic Engineering, China University of Mining \& Technology, Xuzhou, Jiangsu, \\ 221116, China \\ aliyi3@xcmg.com, bvip525@163.com, mxj_xcmg@126.com \\ ${ }^{\star}$ Corresponding author
}

Keywords: 7005 aluminum alloy, Metal inert-gas (MIG),Microstructure, Mechanical property

\begin{abstract}
Metal inert-gas welding of 7005 aluminum alloy profiles was conducted using ER5356 filler wire. The mechanical properties and microstructures of the welding joint were investigated by OM, SEM, micro-hardness test and tensile test. The results show that the tensile strength, yield strength, and elongation of the welding joint are $288 \mathrm{MPa}, 190 \mathrm{MPa}$ and 3.9\%, respectively. The weld zone is characterized by cast structure. The tensile fracture morphology of the welding joint is characterized by ductile rupture. The welded grain near the fusion line is columnar crystals along the radiation direction and the grain in the fusion area is coarse. The fibrous microstructure is found in the base metal, while in the heat affected zone, the recrystallization occurs. The soften zone in the heat affected zone (HAZ), forms due to the coarsening of precipitate phase $\mathrm{Mg}_{2} \mathrm{Si}$.The longer the natural aging time, the greater micro-hardness.
\end{abstract}

\section{Introduction}

Stability and reliability have become the basic design requirements for engineering machinery parts. In the future, it will require higher sustainability such as lightweight, low-carbon, green and intelligence. More and more aluminum alloy are used in the course of weight reduction of engineering machinery [1-3].Al-Zn-Mg alloy with low density, high strength, good process ability and excellent welding properties are widely used in the aerospace industry as well as bridges, buildings and other civilian industry [4-6]. 7005 aluminum alloy belongs to the Al-Zn-Mg-Cu medium-high strength aluminum alloys which can be strengthened by aging treatment [7-9]. They also have good weld ability in high-strength aluminum alloy, but they have a certain degree of stress corrosion tendency [10,11].Metal inert-gas (MIG) welding is being widely utilized to join Al-Zn-Mg alloys [12,13].

Aluminum Alloy is able to withstand high temperatures because of being easily oxidized to form oxide film witch. And they also have high thermal conductivity, high thermal expansion and large crystallization interval[14,15], gas holes and small cracks which would seriously affect the performance of welded components[16], are ubiquitous when welding the aluminum or aluminum alloy with MIG. In this paper, the microstructures and mechanical properties of MIG welding joint of 7005 aluminum were studied, and the effect of natural aging and artificial aging on the properties of welding joint were compared.

\section{Experimental Procedures}

\section{Experimental Materials}

The welding base metal is Al-Zn-Mg-Cu (7005-T5) hollow sections ( $80 \mathrm{~mm} \times 50 \mathrm{~mm} \times 5 \mathrm{~mm})$, and the filler metal is ER5356 with a 1.2mm diameter. Chemical compositions of 7005 aluminum alloy and ER5356 filler metal are presented in table 1. 
Table 1 Chemical composition of 7005 aluminum alloy and ER5356 filler metal

\begin{tabular}{lllllllllll}
\hline \multirow{2}{*}{ Material } & \multicolumn{1}{c}{ Mass fraction(\%) } \\
\cline { 2 - 12 } & $\mathrm{Al}$ & $\mathrm{Zn}$ & $\mathrm{Mg}$ & $\mathrm{Cu}$ & $\mathrm{Si}$ & $\mathrm{Fe}$ & $\mathrm{Mn}$ & $\mathrm{Cr}$ & $\mathrm{Ti}$ & $\mathrm{Zr}$ \\
\hline 7005 aluminum alloy & $\mathrm{Bal}$ & 4.43 & 1.63 & 0.06 & 0.09 & 0.15 & 0.49 & 0.12 & 0.03 & 0.14 \\
ER5356 filler metal & Bal. & 0.09 & 4.92 & 0.015 & 0.13 & 0.14 & 0.138 & 0.102 & 0.102 & - \\
\hline
\end{tabular}

\section{Experimental Equipment and Methods}

ESAB Aristo Mig 5000i welding machine with the pulse function was used. The optimum synergic-pulsed MIG process parameters were listed in table 2.The welding groove type and angle are $\mathrm{V}$ and $90^{\circ}$, respectively. The welding assembly clearance is $2 \mathrm{~mm}$. Before MIG welding, the oxidation film and greasy dirt on the surface of substrates were eliminated by a series of mechanical and chemical cleaning methods. After welding, the samples were cut from the MIG welding joint using a line cut machine.

Table 2 MIG parameters of 7005 aluminum alloy

\begin{tabular}{llll}
\hline Welding current & Welding voltage & Wire feed rate & Argon gas flow \\
$160 \sim 180(\mathrm{~A})$ & $18 \sim 22(\mathrm{~V})$ & $8.6 \sim 9.6\left(\mathrm{~m} \mathrm{~min}^{-1}\right)$ & $15 \sim 18\left(\mathrm{~L} \cdot \mathrm{min}^{-1}\right)$ \\
\hline
\end{tabular}

Micro-hardness test were conducted across the welds using aKB30S type Vickers hardness tester with a load of $200 \mathrm{~g}$ and a dwell time of 10 s. Tensile test was performed according to the ISO 4136:2001standard[17].Tensile test were carried out in SHIMADZU 100kN electronic universal testing machine. The microstructures of the samples and the tensile fracture were analyzed by Leica DMI 5000M type Inverted metallurgical microscope and FEI Inspect S50 type scanning electron microscope (SEM), respectively.

\section{Results and Discussions}

\section{Microstructure}

The microstructure of the welding metal(WM), welding heat affected zone(HAZ) and base metal(BM) are shown inFig.1 (a)、(b) and (c), respectively. As-cast structure with equiaxed shape grains is found in the welding metal (Fig.1 (a)), where the grain size is relatively big. It can be seen from Fig. 1(b) that the columnar grains form in the fusion zone on one side of the welding seam as well as equiaxed crystal on the other side. Most of the heat affected zone retained original structure characteristics of the base metal, and only a fraction of the zone remelted. As seen in Fig.1 (c), the microstructure of 7005 aluminum alloy (BM) is the original rolling state organization.

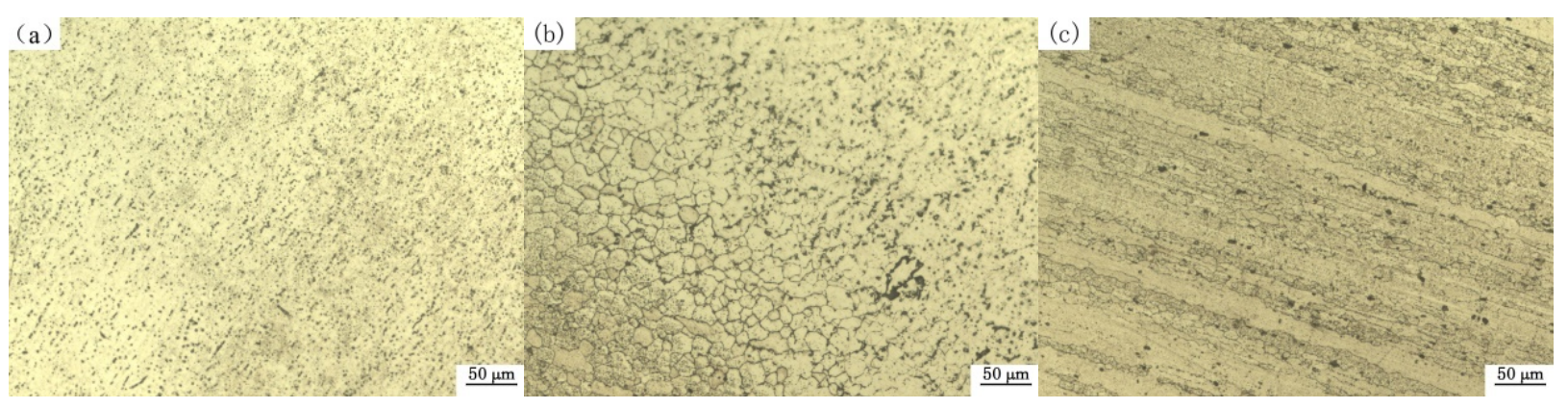

Fig. 1 Microstructures of welding metal(a),fusion zone(b) and base metal(c)

\section{Micro-hardness}

The profile of micro-hardness of the joint is shown in Fig. 2.The micro-hardness is added to study the influence of nature aging time on the mechanical properties of the welded joint. In homogeneity is observed in the MIG welded joint under different NA time. The order of micro-hardness in all NA condition is: $\mathrm{BM}>\mathrm{HAZ}>\mathrm{WM}$. 
The micro-hardness increases with the increased distance from the center, and get the lowest value which is about $70 \mathrm{HV}$ on center part of the weld. But the micro-hardness slightly declined in the softened zone where the distance from the center is about $7 \mathrm{~mm}$. Thus the soften zone in HAZ, which is approximately $7 \mathrm{~mm}$ away from the center of welding seam, forms due to the coarsening of precipitate phase $\mathrm{Mg}_{2} \mathrm{Si}$.In WM where the distance from the center is over10mm, the micro-hardness gets the highest value which is about $120 \mathrm{HV}$. Comparing with these micro-hardness values on different NA time, it is shown that the micro-hardness increased with the NA time increased. This illustrates that there is obvious NA strengthening effect in the MIG welding joints.
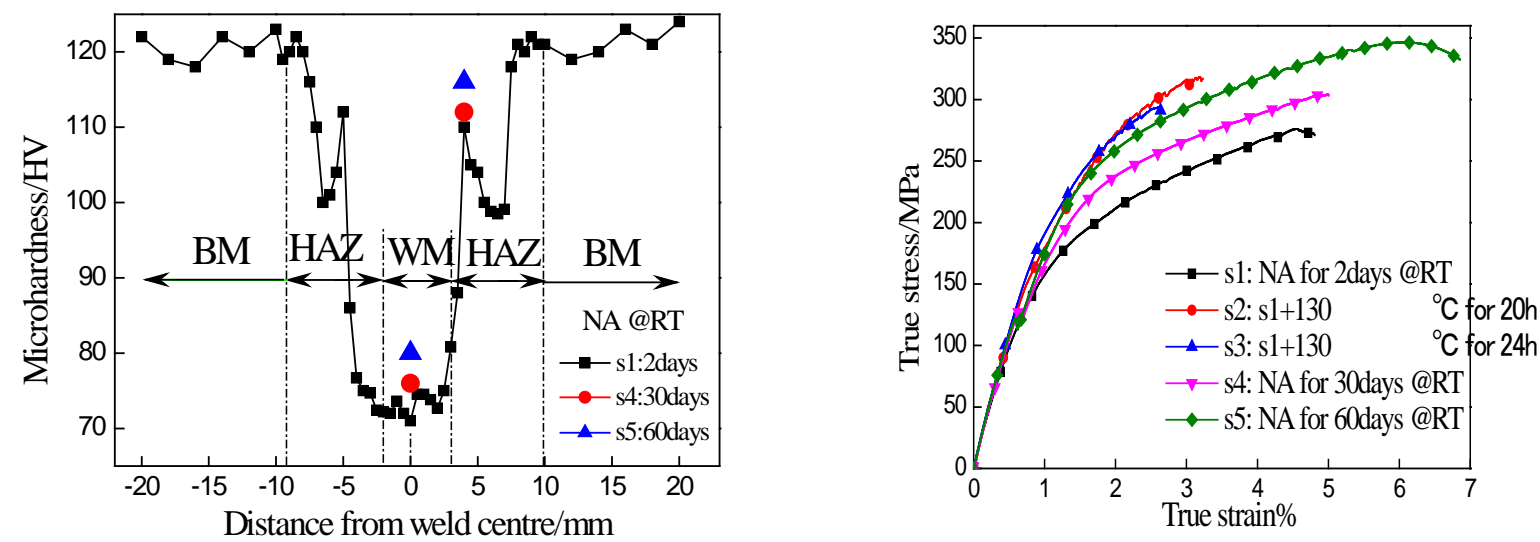

Fig.2Micro-hardness of 7005 aluminum alloy joint.Fig.3Tensile true stress-true strain curves

\section{Tensile test}

The mechanical properties of the welding filler material of 7005aluminum alloy and its welding joint were listed in table 3.The tensile test result in table 3wasthe average of three samples. The tensile true stress-strain curves of the joint samples indifferent conditions were plotted inFig.3.And the No.s1 to s5 corresponding to the state in Fig.3 listed in the condition column of Table 3. It can be seen from table 3 that all the order of the tensile strength, yield strength and elongation is: 7005 base metal $>7005$ welding joint. The tensile samples of welding joint all fail in weld metal, and the strength is much lower than that of base metal. The weld zone is the weakest part in welding joint due to effects of chemical components of filler and crystallization process.

As seen in Fig.3, the order of the tensile strength is: s5>s2>s4>s3>s1. In spite of the difference effect, both natural and artificial aging can improve the strength of the MIG welding joints. The welding joint by the natural aging for 60days has the best tensile strength.

Table 3 Mechanical properties of 7005aluminum alloy and its welding joint

\begin{tabular}{lllrrc}
\hline Sample & No. & Condition & UTS(MPa) & YS(MPa) & A(\%) \\
\hline & s1 & Natural aging for 2days & 288 & 190 & 3.9 \\
& s2 & Natural aging for 2days, then $130^{\circ} \mathrm{C}$ for $20 \mathrm{~h}$ & 308 & 220 & 3.5 \\
7005 joint & s3 & Natural aging for 2days, then $130^{\circ} \mathrm{C}$ for 24h & 286 & 214 & 2.8 \\
& s4 & Natural aging for 30days & 296 & 211 & 5.5 \\
& s5 & Natural aging for 60days & 328 & 227 & 5.6 \\
\hline 7005(BM) & - & T5 & 397 & 343 & 14 \\
\hline ER5356 & - & - & $\geq 265$ & - & - \\
\hline
\end{tabular}

\section{Fracture Analysis}

The tensile fracture morphology of the welding joint and the base metal are shown in Fig. 4 (a)and (b), respectively. It can be seen from Fig. 4(a) that the mode of the tensile fracture is dimple fracture. This indicates that the tensile fracture morphology of the welding joint is characterized by ductile rupture. In addition, the fracture shows that there is no porosity or crack. This illustrates that it is 
not the defects such as the porosity or crack but the low tensile strength which lead the specimens to fracture. As seen in Fig.4(b), the mode of the tensile fracture is also dimple fracture. Comparing with the dimple fracture of the welding joint, the dimple fracture of the base metal is smaller and shallower, and the dimple structure is less obvious. In addition, the cleavage steps were found on the tensile fracture of the base metal. The fracture of the base metal shows quasi-cleavage.

Though the plasticity and toughness of the welding joint are better than that of the base metal, the elongation of the welding joint is less than that of the base metal. This is because the tensile strength is too low to resist deformation. The local deformation leads to crack before the homogeneous deformation was completely done.

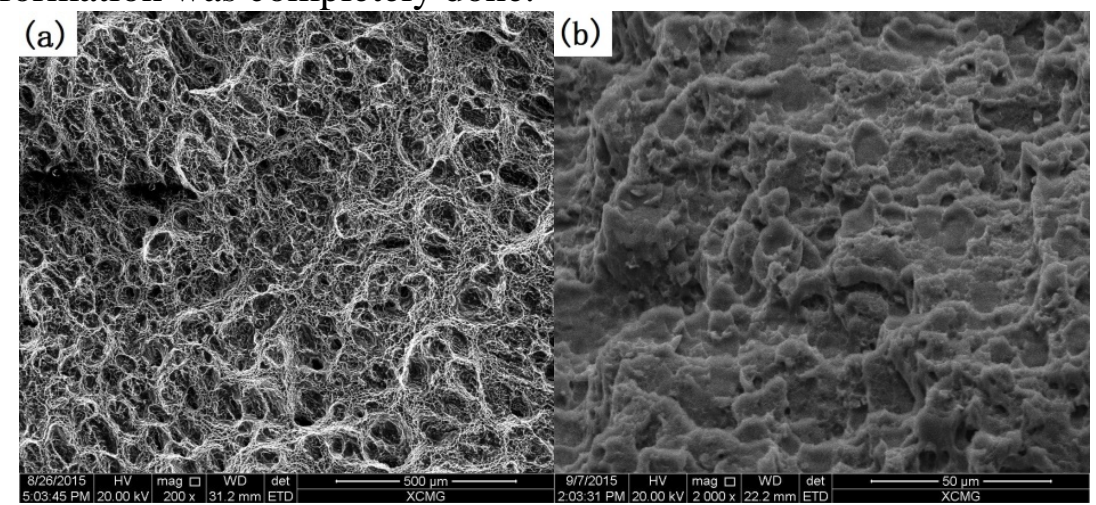

Fig. 4 SEM images of tensile fracture sample in7005Al alloy joint (a) and base metal (b)

\section{Conclusions}

In this paper the microstructures and mechanical properties of MIG welding joint of 7005 aluminum alloy are studied. And a comparative analysis of the microstructures and mechanical properties between welding joint and the base metal is also investigated. The following conclusions are drawn:

(1) The welding metal has an as-cast structure with equiaxed shape grains. And the columnar grains form in the fusion zone on one side of the welding seam as well as equiaxed crystal on the other side. The microstructure of the base metal is the original rolling state organization.

(2) The order of micro-hardness in the joint sample is: BM $>$ HAZ $>W M$. The micro-hardness increases with the increased distance from the center, though the micro-hardness is slightly declined in the softened zone. The longer the natural aging time, the greater micro-hardness.. There is obvious NA strengthening effect in the MIG welding joints.

(3) The tensile strength, yield strength, and elongation of the welding joint (Natural aging for 2days) are $288 \mathrm{MPa}, 190 \mathrm{MPa}$ and3.9\%, respectively. By artificial aging treatment at $130^{\circ} \mathrm{C}$ for $20 \mathrm{~h}$ and natural aging for 60days, the tensile strength may reach308 MPa and $328 \mathrm{MPa}$, respectively. The tensile fracture morphology of the welding joint is characterized by ductile rupture. Comparing with the dimple fracture of the welding joint, the dimple fracture of the base metal is smaller and shallower, and the dimple structure is less obvious. The cleavage steps is found on the tensile fracture of the base metal. The fracture of the base metal shows quasi-cleavage.

\section{Acknowledgement}

The authors are grateful to Hong-fang ZHANG and Yan-hong JING for providing ESAB facility and detection device to carry out this investigation.

\section{References}

[1] TolgaDursun, Costas Soutis. Recent developments in advanced aircraft aluminum alloys, J. Mater. Des.56 (2014) 862-871.

[2] Hong WANG, Gao-fengFU, Ji-hong SUN, Xing-jieLI, Lan JIANG. Present research and developing trends of ultra-high strength aluminum alloys, J. Mater. Rev.20(2006) 58-60. 
[3] I.N. Fridlyander, O.G. Senatorova. Development and application of high-strength Al-Zn-Mg-Cu alloys, J. Mater. Sci. Forum. (22) 217(1996) 1813-1818.

[4]Yu-tang WANG, Rong-zhangTIAN. Aluminum Alloy and Its Processing, third ed., Central South University Press, Changsha, 2000.In Chinese.

[5] Fu-sheng PAN, Ding-feiZHANG. Aluminum Alloy and Application, first ed., Chemical Industry Press, Beijing, 2006.In Chinese.

[6] Wei-weiLI, Xiao-qingZUO, Zhan-yongLIU, HU Song. Microstructure Characteristics and Research Progress of High Strength andHigh Toughness Aluminum Alloy, J. Hot Working Technology.(10) 44(2015)12-15. In Chinese.

[7] P A ROMETSCH, Y ZHANG, S KNIGHT. Heat treatment of 7xxx series aluminium alloys-Some recent developments, J. Transactions of Nonferrous Metals Society of China. (7) 24 (2014)2003-2017.

[8] Yu-guo LIAO, Xiao-qi HAN, Miao-xia ZENG, Man JIN. Influence of Cu on microstructure and tensile properties of 7xxx series aluminum alloy, J. Materials \& Design B. 66 (2015) 581-586.

[9]Liang ZHANG, Xiao-yanLI, Zuo-renNIE, Hui HUANG, Jian-tong SUN.Microstructure and mechanical properties of a new Al-Zn-Mg-Cu alloy joints welded by laser beam, J. Materials \& Design. 83 (2015) 451-458.

[10] Lalpoor M, Eskin D G, Katgerman L. Fracture behavior and mechanical properties of high strength aluminum alloys in the as-cast condition, J. Materials Science and Engineering. A497 (2008) 186-194.

[11] Gómez de Salazar J M,Barrena M I. Role of $\mathrm{Al}_{2} \mathrm{O}_{3}$ particulate reinforcements on precipitation in 7005 Al-matrix composites, J. ScriptaMaterialia.44 (2001) 2489-2495.

[12] J Z LIU, J HCHEN, X B YANG, et a1. Revisiting the precipitationsequence in A1-Zn-Mg based alloys by high-resolution transmission electron microscopy, J. ScriptaMaterialia. (11)63 (2010) 1061-1064.

[13] Tian-wen ZHAO, Yanyao JIANG, Fatigue of 7075-T651 aluminum alloy, J. International Journal of Fatigue. 30 (2008) 834-849.

[14] P. Witzendorff, J. Hermsdorf, S. Kaierle, O. Suttmann, L. Overmeyer. Double pulse laser welding of 6082 aluminum alloys.J. Sci. Technol. Weld. Joining.20(2015)42-47.

[15] D.X. YANG, X.Y. LI, D.Y. HE, H. HUANG, L. ZHANG. Study on microstructure and mechanical properties of Al-Mg-Mn-Er alloy joints welded by TIG and laser beam, J. Mater. Des., 40 (2012)117-123.

[16] DUDZIK K. Influence of joining method for hardnessdistribution in joints of $\mathrm{AlZn}_{5} \mathrm{Mg}_{1}$ alloy, J. Journal of KONESPowertrain and Transport. (4) 17(2010)137-141.

[17] ISO 4136:2001.International standard.Destructive tests on welds in metallic materials -transverse tensile test. 